\title{
Levels of nicotine dependence in the elderly and cognitive impairment
}

\author{
Ricardo Luís de Aguiar Assis,' Bruno Terra Junho,' Valdir Ribeiro Campos 1,2
}

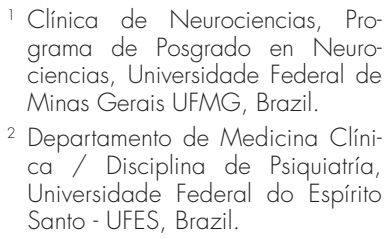

2 Departamento de Medicina Clínica / Disciplina de Psiquiatría, Universidade Federal do Espírito Santo - UFES, Brazil

\section{Correspondence:}

Ricardo Luís de Aguiar Assis

Clinical Neurosciences, Postgraduate

Program in Neurosciences,

Universidade Federal de Minas

Gerais UFMG, Brazil.

Antônio Carlos Avenue, 6627,

Pampulha, Belo Horizonte,

Minas Gerais, Brazil.

Phone: (31) 3409 - 2545

CEP: 31270 - 901

Email: ricardo.aguiarassis@gmail.com

Received: 7 November 2019

Accepted: 6 May 2020

\section{Citation:}

de Aguiar Assis, R. L., Terra Junho, B. \& Ribeiro Campos, V. (2020). Levels of nicotine dependence in the elderly and cognitive impairment. Salud Mental, 43(4), 159-166

DOI: $10.17711 /$ SM.0185-3325.2020.022

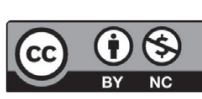

\begin{abstract}
Introduction. Health problems in elderly individuals are diverse. The use of cigarettes, a potentially addictive substance, has been increasing in the elderly population age group, affecting the cognitive and elderly domains, and becoming an important global public health problem. Objective. This study aimed to investigate the relationship between tobacco consumption by the elderly, as well as different levels of nicotine dependence and cognitive domains of executive functions. Method. It is a case-control study composed by 58 individuals aged $\geq 60$ years, with 29 participants in the clinical group and 29 in the control group. The case-control sample was paired in subgroups by sex, socioeconomic status, schooling, and sample isonomy with the clinical group. We used the Shapiro-Wilk normality test, the Mann-Whitney test, the student T-test, and the Cohen d-estimator. Results. The control group performed better compared to the clinical group with the median grade in the inhibitory control of the executive domain with Cohen's $d 1.00$ in the five-digit test and Cohen's 1.5 in the Stroop test. The control group compared with the high-grade clinical group presented better performance with Cohen's working memory of $1.56 \mathrm{~d}$, Cohen's inhibition of $1.06 \mathrm{~d}$ in the five-digit test, and Cohen's of $1.17 \mathrm{~d}$ in the Stroop test. Discussion and conclusion. The detection of the level of nicotine dependence is associated with the degree of cognitive impairment in the specific executive domain, which provides a possibility of differential diagnosis, both in the clinical and population contexts, directed at the rehabilitation of executive domains most affected by smoking in the elderly.
\end{abstract}

Keywords: Tobacco, nicotine dependence, cognitive domains.

\section{RESUMEN}

Introducción. Los problemas de salud en las personas mayores son diversos. El consumo de tabaco, una sustancia potencialmente adictiva, ha aumentado en el grupo de edad de la población de ancianos, afectando los dominios cognitivos y de ancianos, convirtiéndose en un importante problema de salud pública mundial. Objetivo. Este estudio tuvo como objetivo investigar la relación entre el consumo de tabaco en los ancianos, los diferentes niveles de dependencia de la nicotina y los dominios cognitivos de las funciones ejecutivas. Método. Es un estudio de casos y controles, compuesto por 58 individuos de $\geq 60$ años, con 29 participantes en el grupo clínico y 29 en el control. La muestra de casos y controles se emparejó en subgrupos por sexo, nivel socioeconómico, escolaridad e isonomía de la muestra con el grupo clínico. Se utilizaron la prueba de normalidad Shapiro-Wilk, la prueba de Mann-Whitney, la prueba Student $T$ y el estimador d de Cohen. Resultados. El grupo de control se desempeñó mejor en comparación con el grupo clínico con el grado medio en el control inhibitorio del dominio ejecutivo con Cohen's d 1.00 en la prueba de cinco dígitos y Cohen's 1.5 en la prueba de Stroop. En comparación con el grupo clínico de alto grado, el grupo de control presentó un mejor rendimiento con la memoria de trabajo de Cohen de $1.56 \mathrm{~d}$, la inhibición de Cohen de $1.06 \mathrm{~d}$ en la prueba de cinco dígitos y la de Cohen de $1.17 \mathrm{~d}$ en la prueba de Stroop. Discusión y conclusión. La detección del nivel de dependencia de la nicotina se asocia con el grado de deterioro cognitivo en el dominio ejecutivo específico, lo que brinda la posibilidad de un diagnóstico diferencial, tanto en el contexto clínico como en el de la población, dirigido a la rehabilitación de los dominios ejecutivos más afectados por el tabaquismo en los ancianos.

Palabras clave: Tabaco, dependencia a la nicotina, dominios cognitivos. 


\section{INTRODUCTION}

The health problems in elderly individuals senescence are diverse, but one category stands out, potentially addictive drugs: the consumption of alcohol, tobacco, and psychoactive medicines. The higher the consumption of these substances, the greater the risks associated with health problems (Wang \& Andrade, 2013). The use of cigarettes, a potentially addictive substance, has been increasing among the elderly population age group, becoming an important global public health problem (Wolf, Du, \& Knopf, 2017).

The World Health Organization, through a report released in 2015, emphasized that healthy aging consists not only of the absence of disease but of maintaining the cognitive and functional abilities of the elderly to provide integrated quality of life between the individual and their psychosocial interactions (Organização Mundial de Sáude, 2015). In this way, smoking, as a substance that damages cognitive functions, also potentiates the quality of life deficits in a healthy aging process.

A study by North et al. (2015) concluded that smoking was associated with poorer cognitive performance through the evaluation of eight different cognitive tests and five measures of cognitive decline. However, the association between smoking and cognitive measures may be influenced by covariables such as age, level of education, socioeconomic level. Aguilar-Navarro, Reyes-Guerrero, and Borgues (2007) studied and 4872 elderly individuals aged 65 or over in Mexico. In this study, the association of the current use of tobacco and/or in the previous life of the subjects with cognitive impairments was not observed. This demonstrated that the correlations between cognitive impairment and tobacco consumption in the elderly population need more advanced studies due to covariables of this age group that would influence cognitive performance.

Some factors are referred to as protective in aging, one of them is physical activity, which promotes an improvement in the quality of life. Studies have shown a correlation between physical activity practiced by the elderly and better performance in the executive functions (Scherder et al., 2005; Borges, Rech, Meurer, \& Benedetti, 2015). Another factor is the nutritional state of the individual, which is also important to maintain their well-being. Nutritional changes can interfere from the physiological to the cognitive systems; studies show correlations between nutritional status and the maintenance or decay of cognitive functions (Pereira, Spyrides, \& Andrade, 2016).

However, in the aging process, certain mental health problems lead to the use of potentially addictive drugs. In an epidemiological study conducted by Cantão et al. (2015) in Brazil, it was observed that elderly people with depressive disorders are more likely to use substances, such as alcohol and cigarettes, and also highlighted a higher prevalence of cigarette use among female elderly.
Tobacco consumption exposes the individual to various substances, in addition to nicotine, such as polycyclic aromatic hydrocarbon particles. Through urinary biomarkers measurements in 454 elderly people, Best, Juarez-Colunga, James, LeBlanc, and Serdar (2016) concluded that the use of tobacco in this population increases cognitive impairment by $1.8 \%$.

The evaluation of the effect of tobacco use on the cognition of the elderly population does not yet have for the time being a scientific casuistic model and the empirical studies that evaluated the association between the degree of nicotine dependence and the cognitive constructs that compose the executive functions presented problems in the results due to difficulties in evaluating the complex cognitive abilities and covariates of this age group that influence it. In view of this, the resulting problem emerges from the impact that smoking different levels of nicotine dependence exerts on such executive functions in the elderly differentially in each cognitive domain (Almeida, Hankey, Yeap, Golledge, \& Flicker, 2014; Patil, Suryanarayana, Dinesh, Shivraj, \& Murthy, 2015).

Executive functions involve three main constructs: inhibitory control, working memory, and cognitive flexibility. Inhibitory control corresponds to the ability to exercise directed self-control of behavior and involves the participation of cognitive processes, such as attention, emotional control, and self-regulation of behavior. Working memory, on the other hand, is the ability to use information stored in the present moment to promote a general understanding of mental elements from fragmented ideas. In turn, Cognitive flexibility refers to the ability to change the perspective of thinking about a problem and to be flexible in admitting errors by changing strategies in the execution of directed behavior. It is important to emphasize that these functions are essential in the cognitive function of any individual (Diamond, 2013).

The aim of this study is to investigate the relationship between levels of nicotine dependence per elderly and the cognitive domains that make up the executive functions.

\section{METHOD}

This is a case-control study carried out at the Irmã Denise School Hospital, Minas Gerais, Brazil.

The inclusion criteria of the clinical group were: age between 60 to 90 and cigarette use. The inclusion criteria of the control group were: age between 60 and 90 years and no cigarettes use ever. Exclusion criteria for both groups were defined as the presence of severe perceptual-motor deficits, neuropsychiatric disorders, neurological disorders, severe cardiac or renal insufficiency, acute confusional state, diabetes mellitus, and hypothyroidism.

The study was carried out from November 2017 to July 2018. In the first stage, elderly outpatients at the Irmã 
Denise School Hospital were invited to participate in the present study. Next, a socioeconomic interview and a geriatric clinical screening were performed according to the protocol defined by Campos, Lisboa, and Westin (2014). A cognitive screening using the Mental State Mini Exam, modified by Melo and Barbosa (2015), was also applied. The modules of mood and anxiety disorder of the Mini International Neuropsychiatric Interview (MINI Plus 5.0), adapted to Brazil by Amorim (2000), were also used. These procedures aimed to meet the study inclusion/exclusion criteria applied to both groups.

Subsequently, the Fagerström Nicotine Dependence Test (FTND) was applied. This test consists of a questionnaire of five questions, and for each alternative there is a score whose sum makes up the total score. From this score the degree of nicotine dependence is determined, being presented in the following levels: very low ( 0 to 2 points); low (3 to 4 points); average (5 points); high (6 to 7 points); and very high (8 to 10 points) (Barbosa, Pereira, Cruz, \& Leite, 2018). The FTND was important for the separation of the clinical group from the control group and still used its parameters to establish the levels of nicotine dependence within the clinical group.

The clinical group was monitored for 15 days by the multidisciplinary team of the school-hospital through a home visit every three days, which was the necessary time of abstinence for neuropsychological testing, (Salgado et al., 2009; Farhadian, Akbarfahimi, Hassani Abharian, Hosseini, $\&$ Shokri, 2017). The neuropsychological evaluation was performed in two sessions of one hour each in both groups.

\section{Neuropsychological evaluation instruments}

\section{Phonemic Verbal Fluency Test}

In the Phonemic Verbal Fluency Test, participants are asked to verbalize the largest number of words that begin with the letters "F," "A," and "S" within one minute for each letter. No proper nouns are counted, such as names of people, cities, and countries. This test seeks to evaluate the working memory, phonemic loop (Machado et al., 2009). The score is formed by the number of words pronounced and not repeated for one minute for each letter.

\section{Five Digit Testing (FDT)}

This test consists of two parts: the subtest choice and the alternation. In the first, which affects the cognitive domain inhibitory control, the participant should inhibit the reading of the numbers presented and say how many numbers exist in each stimulus, presented this time incongruously (when the subject finds 2-2-2, he/she should say "three." Or when he/she finds 1-1-1-1, he/she should say "four"). The second evaluates cognitive flexibility. In this subtest, a group of digits delimited by a thicker border is presented to the individual and oriented to alternate performing two operations, counting items or reading the numbers (Campos, Silva, Florêncio, \& Paula, 2016). The score is formed by the time that the individual takes to perform each subtest.

\section{Stroop Victoria Test}

The Stroop Test, Victoria version, consists of three cards measuring $18 \times 11.5 \mathrm{~cm}$, containing 24 stimuli each, printed on a white background. Card 1 consists of 24 rectangles arranged in six rows of four items, with a spacing of $1 \mathrm{~cm}$ between rows and $2 \mathrm{~cm}$ between the items. The rectangles are printed in the colors green, pink, blue, and brown so that each color appears only once per race in a random arrangement. In card 1, the task is to name the rectangle colors as quickly as possible. In card 2, there are words inside the rectangles, that are not related to concepts of color (each, never, today, everything) printed in capital letters and randomly arranged in green, pink, blue, and brown colors. In this card, the task is to name the colors of the words (ignoring the words) as quickly as possible. Card 3 is the interference card where the stimuli are color names (brown, blue, pink, and green) printed in capital letters in green, pink, blue, and brown, such that the ink color of the print and the name of the color never match. In it, the subject is asked to name the print colors (ignoring to read the names of the colors) as fast as possible. The purpose of this evaluation is to test for inhibitory control (Duncan, 2006). The score is formed by the time of accomplishment of the task.

\section{Evaluation of protective factors for the cognition of the elderly}

\section{Mini Nutrition Assessment (MNA)}

MNA is a nutritional assessment tool to identify nutritional status in individuals. It consists of a questionnaire divided into four parts: anthropometric evaluation (body mass index, arm circumference, calf circumference, and weight loss); global assessment (questions related to lifestyle, medication, mobility, and psychological problems); dietary assessment (questions related to number of meals, food and fluid intake and autonomy in food); and self-perception of health and nutritional status (Hengstermann, Nieczaj, Steinhagen-Thiessen, \& Schulz, 2008). This evaluation allows the individual to be classified in: (0) normal nutritional status; (1) risk of malnutrition; (2) malnourished.

\section{International Physical Activity Questionnaire (IPAQ)}

IPAQ adapted for the elderly is composed of the same domains of the original IPAQ, but presents a smaller number of questions because of the questions related to the "days of the week" and the "time (min/hours/day)" of physical activity (Mazo \& Benedetti, 2010). The time score represented minutes of performing daily physical activities. 


\section{Statistical analysis}

The discrete variables were expressed as absolute frequency $(n)$ and relative frequency (\%) while the continuous variables were expressed in mean and standard deviation. The normality of the sample was evaluated by the Shapiro-Wilk test and the Levene test for homogeneity of variance (Tabachnick \& Fidell, 2013).

Correlations between analyzed variables were measured using the Pearson correlation test. The hypothesis test for independent samples was performed using Student's $t$ test for samples with normal distribution and the Mann-Whitney test for samples without this distribution (Field, 2013). Calculations were performed with SPSS software (Statistical Package for Social Sciences), version 22.0.

\section{Ethical Considerations}

The project was approved by the Research Ethics Committee with human beings of the University Center of Caratinga, Protocol 2,305,987, in accordance with the National Health Council Law No. 196/96 (CAAE: 77158217.4.0000.5114).

\section{RESULTS}

The initial clinical sample consisted of 34 elderly patients. However, five participants were excluded because they did not remain in nicotine withdrawal for the period necessary for neuropsychological testing. Thus, the analyzed sample consisted of 29 individuals aged over 60 years diagnosed by the FTND with different levels of nicotine dependence. The levels, very low, low, medium, and high degree, of nicotine dependence presented $8,7,6$, and 8 individuals, respectively. The control group consisted of 29 participants who had never smoked. The profile of the sample is summarized in Table 1.

A comparison was made between the physical activity level of the clinical elderly groups compared to the control elderly groups. In this hypothesis test, no significant variation was observed, using both the raw scores and the Z-scores. Thus, it can be considered that the variable physical activity does not have a difference between the groups.

A comparison was also made between the nutritional status of the clinical elderly groups compared to the control elderly groups. Using the hypothesis test, it was observed that there was no significant variation of this factor between the groups, using both the raw and the Z-scores scores. Z-score was implemented because the variable physical activity is continuous and the nutritional status variable is ordinal, so Z-score provided a single standard for a better understanding of the variables results. Therefore, it can be considered that the nutritional status variable does not have a difference between the groups. The results on the variables physical activity and nutritional status are described in Table 2.

Elderly individuals with a mean degree of nicotine dependence had a significant difference, compared to the control group, in the following domains of executive functions: worse performance in the cognitive function inhibitory control with Cohen's d of 1.0 as measured by Cohen's five-digit ed test measured by the Stroop test, Victoria version. The working memory domains and cognitive flexibility did not reach a significant difference compared to the respective control subgroups as observed in Table 3.

The clinical sample with a high degree of nicotine dependence obtained a significant difference compared with

Table 1

Sample description

\begin{tabular}{|c|c|c|c|c|c|c|c|}
\hline & \multirow{2}{*}{$\begin{array}{c}\text { No cigarette use } \\
\text { Abstainers }\end{array}$} & \multicolumn{5}{|c|}{ Cigarette use } & \multirow[b]{2}{*}{$X^{2}$} \\
\hline & & very low & low & medium & high & Total & \\
\hline Female & $18(n)$ & $6(n)$ & $1(n)$ & $3(n)$ & $3(n)$ & $31(n)$ & .11 \\
\hline Male & $11(n)$ & $2(n)$ & $6(n)$ & $3(n)$ & $5(n)$ & $27(n)$ & .11 \\
\hline Total & $29(n)$ & $8(n)$ & $7(n)$ & $6(n)$ & $8(n)$ & $58(n)$ & \\
\hline Age $M(S d)$ & $67.41 \pm 6.65$ & $70.75 \pm 6.13$ & $63.57 \pm 2.70$ & $65.17 \pm 4.85$ & $68.88 \pm 7.60$ & & .29 \\
\hline Retired & $20(n)$ & $7(n)$ & $3(n)$ & $4(n)$ & $6(n)$ & & .45 \\
\hline Still work & $9(n)$ & $1(n)$ & $4(n)$ & $2(n)$ & $2(n)$ & & .45 \\
\hline Incomplete middle school & $13(n)$ & $4(n)$ & $3(n)$ & $5(n)$ & $1(n)$ & & .02 \\
\hline Complete midle school & $8(n)$ & $0(n)$ & $1(n)$ & $0(n)$ & $7(n)$ & & .02 \\
\hline Incomplete high school & $5(n)$ & $4(n)$ & $0(n)$ & $1(n)$ & $0(n)$ & & .02 \\
\hline Complete high school & $1(n)$ & $0(n)$ & $1(n)$ & $0(n)$ & $0(n)$ & & .02 \\
\hline Complete higher education & $1(n)$ & $0(n)$ & $1(n)$ & $0(n)$ & $0(n)$ & & .02 \\
\hline Incomplete middle school & $1(n)$ & $0(n)$ & $1(n)$ & $0(n)$ & $0(n)$ & & .02 \\
\hline Economic income: 1 Minimum wage & $7(n)$ & $1(n)$ & $1(n)$ & $3(n)$ & $2(n)$ & & .23 \\
\hline Economic income: 2 to 3 Minimum wage & $17(n)$ & $6(n)$ & $5(n)$ & $1(n)$ & $5(n)$ & & .23 \\
\hline Economic income: 2 to 3 Minimum wage & $5(n)$ & $1(n)$ & $1(n)$ & $2(n)$ & $1(n)$ & & .23 \\
\hline
\end{tabular}


Table 2

Physical activity and nutritional status of the elderly of the clinical groups compared to the elderly of the control groups

\begin{tabular}{|c|c|c|c|c|c|c|c|c|c|c|c|c|}
\hline & \multicolumn{12}{|c|}{ Mann Whitney Test } \\
\hline & Very low & Abstainers & $p$ & Low & Abstainers & $p$ & Medium & Abstainers & $p$ & High & Abstainers & $p$ \\
\hline $\begin{array}{l}\text { Physical Activity } \\
\text { Level (IPAQ) M (Sd) }\end{array}$ & $\begin{array}{c}264.00 \\
\pm 380.87\end{array}$ & $\begin{array}{c}141.87 \\
\pm 117.22\end{array}$ & .878 & $\begin{array}{c}223.57 \\
\pm 189.53\end{array}$ & $\begin{array}{c}119.28 \\
\pm 106.16\end{array}$ & .209 & $\begin{array}{c}254.44 \\
\pm 272.86\end{array}$ & $\begin{array}{c}124.16 \\
\pm 115.43\end{array}$ & .485 & $\begin{array}{r}208.75 \\
\pm 137.86\end{array}$ & $\begin{array}{c}141.88 \\
\pm 117.22\end{array}$ & .382 \\
\hline Median & 76 & 90 & & 165 & 90 & & 180 & 82.50 & & 217.50 & 90 & \\
\hline Zscore & $.21 \pm 1.36$ & $-.22 \pm 04$ & & $.33 \pm 1.20$ & $-.33 \pm .67$ & & $.30 \pm 1.29$ & $-.30 \pm .54$ & & $.26 \pm 1.07$ & $-.26 \pm .91$ & \\
\hline Median Zscore & -.45 & -.40 & & -.04 & -.51 & & -.04 & -.50 & & .32 & -.66 & \\
\hline $\begin{array}{l}\text { Nutritional Status } \\
\text { (MNA) M (Sd) }\end{array}$ & $.63 \pm .51$ & $.65 \pm .53$ & 1.00 & $.29 \pm .48$ & $.71 \pm .48$ & .165 & $.83 \pm .75$ & $.67 \pm .51$ & .818 & $.50 \pm .75$ & $.63 \pm .51$ & .574 \\
\hline Median & 1 & 1 & & 0 & 1 & & 1 & 1 & & 0 & 1 & \\
\hline Zscore & $0 \pm 1.03$ & $0 \pm 1.05$ & & $-.41 \pm .94$ & $.41 \pm .94$ & & $.13 \pm 1.21$ & $-.13 \pm .83$ & & $-.09 \pm 1.20$ & $-.09 \pm .82$ & \\
\hline Median Zscore & .75 & .76 & & -.96 & .96 & & .40 & .40 & & -.89 & .69 & \\
\hline
\end{tabular}

the control group in the following domains of executive functions: worse performance in work memory measured by the Phonemic Fluency "FAS" test with Cohen's d of 1.56. This sample also showed a worse performance in the cognitive control inhibitory function with Cohen's d of 1.06 as measured by the five-digit Cohen's Choice and d test 2.17 as measured with the Stroop test, Victoria version. The cognitive flexibility domain measured by the five-digit test did not achieve a significant difference compared to the control group.

There were no statistically significant differences between the groups that had very low and low dependence compared to the control group. The results of the neuropsychological tests are found in Table 3.

The working memory was evaluated with the phonemic fluency test "FAS". In this test, the score is measured by the number of verbalized words, thus, the higher the score, the better is the performance. Cigarette-smoking elders demonstrate worse performance only among the high nicotine addiction level group. The effect size difference between the control and clinical Cohen's $1.56 \mathrm{~d}$ group.

Inhibitory control was evaluated with the Five Digits test and the Stroop version. In both tests, the measured score is through the time of accomplishment of the task: the small-

Table 3

Comparison between Clinical Group: Grade-dependent nicotine, and Control Group: abstemious cigarette consumption

\begin{tabular}{|c|c|c|c|c|c|c|c|c|c|c|c|c|c|c|}
\hline & \multicolumn{14}{|c|}{ Student's t Test } \\
\hline & \multirow{2}{*}{\multicolumn{2}{|c|}{ Very low Abstainers }} & \multirow[b]{2}{*}{$P$} & \multirow[b]{2}{*}{ Low } & \multirow[b]{2}{*}{ Abstainers } & \multirow[b]{2}{*}{$P$} & \multirow[b]{2}{*}{ Medium } & \multirow[b]{2}{*}{ Abstainers } & \multirow[b]{2}{*}{$P$} & \multicolumn{2}{|c|}{ Cohen's } & \multirow[b]{2}{*}{ Abstainers } & \multirow[b]{2}{*}{$P$} & \multirow{2}{*}{$\begin{array}{c}\text { Cohen's } \\
d\end{array}$} \\
\hline & & & & & & & & & & $d$ & High & & & \\
\hline $\begin{array}{l}\text { Working Memory } \\
\text { (Phonemic Verbal } \\
\text { Fluency Test) } \\
\mathrm{M}(S d)\end{array}$ & $\begin{array}{c}8.25 \\
\pm 3.77\end{array}$ & $\begin{array}{c}8.76 \\
\pm 3.62\end{array}$ & .826 & $\begin{array}{c}7.78 \\
\pm 4.39\end{array}$ & $\begin{array}{c}8.72 \\
\pm 3.22\end{array}$ & .779 & $\begin{array}{c}6.67 \\
\pm 3.14\end{array}$ & $\begin{array}{c}8.54 \\
\pm 2.92\end{array}$ & .098 & & $\begin{array}{c}4.57 \\
\pm 2.57\end{array}$ & $\begin{array}{c}8.86 \\
\pm 3.62\end{array}$ & .025 & 1.56 \\
\hline & \multicolumn{14}{|c|}{ Mann-Whitney Test } \\
\hline $\begin{array}{l}\text { Inhibitory Control } \\
\text { (5-digit test } \\
\text { Choose) } \\
\mathrm{M}(S d)\end{array}$ & $\begin{array}{c}84.33 \\
\pm 36.67\end{array}$ & $\begin{array}{c}79.13 \\
\pm 29.43\end{array}$ & .162 & $\begin{array}{c}131.50 \\
\pm 122.99\end{array}$ & $\begin{array}{c}63.43 \\
\pm 20.69\end{array}$ & .110 & $\begin{array}{c}197.57 \\
\pm 188.92\end{array}$ & $\begin{array}{c}63.43 \\
\pm 20.69\end{array}$ & .017 & 1.00 & $\begin{array}{c}223.75 \\
\pm 189.93\end{array}$ & $\begin{array}{c}79.13 \\
\pm 29.43\end{array}$ & .038 & 1.06 \\
\hline Median & 79.00 & 59.00 & & & 59.00 & & 140.50 & 62.00 & & & 135.00 & 59.00 & & \\
\hline $\begin{array}{l}\text { Inhibitory Control } \\
\text { (Stroop Victoria } \\
\text { Test) } \\
\mathrm{M}(S d)\end{array}$ & $\begin{array}{c}57.57 \\
\pm 42.58\end{array}$ & $\begin{array}{c}23.14 \\
\pm 16.96\end{array}$ & .083 & $\begin{array}{c}63.63 \\
\pm 48.50\end{array}$ & $\begin{array}{c}28.25 \\
\pm 10.74\end{array}$ & .061 & $\begin{array}{c}57.50 \\
\pm 39.42\end{array}$ & $\begin{array}{c}14.13 \\
\pm 10.81\end{array}$ & .038 & 1.5 & $\begin{array}{c}86.75 \\
\pm 42.82\end{array}$ & $\begin{array}{c}19.00 \\
\pm 10.56\end{array}$ & .021 & 2.17 \\
\hline Median & 58.00 & 19.00 & & 41 & 10.74 & & 57.50 & 40.00 & & & 88.50 & 13.50 & & \\
\hline $\begin{array}{l}\text { Cognitive } \\
\text { Flexibility (5 Digit } \\
\text { Test Switching) } \\
\mathrm{M}(S d)\end{array}$ & $\begin{array}{c}135.38 \\
\pm 126.00\end{array}$ & $\begin{array}{r}116.63 \\
\pm 24.47\end{array}$ & .162 & $\begin{array}{c}211.50 \\
\pm 202.98\end{array}$ & $\begin{array}{c}97.14 \\
\pm 40.92\end{array}$ & .180 & $\begin{array}{c}259.63 \\
\pm 220.65\end{array}$ & $\begin{array}{c}84.33 \\
\pm 36.67\end{array}$ & .090 & & $\begin{array}{c}280.67 \\
\pm 254.49\end{array}$ & $\begin{array}{r}116.63 \\
\pm 24.47\end{array}$ & .069 & \\
\hline Median & 99.50 & 119.00 & & 140.50 & 108.00 & & 178.00 & 79.00 & & & 178.00 & 119.00 & & \\
\hline
\end{tabular}

Note: $P<.005$ 
er the time spent, the better is the performance. The control group presented a better performance compared to two clinical subgroups: the clinical group with a medium degree of dependence and the group with a high-degree of dependence. The effect size of the performance difference between the groups was: control and medium degree of dependence clinical group $\mathrm{d}$ of Cohen 1.00 in the Five-Digit test and $\mathrm{d}$ of Cohen's 1.5 in the Stroop test; control and high dependence clinical group $\mathrm{d}$ of Cohen 1.06 in the five-digit test and Cohen's $d 1.17$ in the Stroop test. We observed that the cognitive impairment of the inhibitory control in the high nicotine dependent group was higher than in the median group, and we also noted that there was a difference in the measures of the tests that measure the same inhibitory control construct.

Cognitive flexibility was assessed by the Five Digit Alternation test. In this test, time is the measure of the score; thus, the shorter the time, the better the performance. The clinical sample of the very low, low, medium, and high nicotine dependence group did not show significant differences compared to the respective control groups.

\section{DISCUSSION AND CONCLUSION}

The consumption of cigarettes enables contact to a multitude of chemical compounds, standing out nicotine due to its addictive potential. This substance has short-term actions on the cholinergic system, having an important effect on the executive functions. Many studies on smoking-related brain functions have been performed with neuropsychological screening measures, which leads to doubtful data, and also hampers investigations with large clinical or epidemiological samples (Swan \& Lessov-Schlaggar, 2007).

In this study, careful clinical and cognitive screening followed the evaluation of the degree of nicotine dependence with the FTND. Finally, neuropsychological testing was carried out with specific measures to measure the cognitive domains of executive functions that evaluated inhibitory control, working memory, and cognitive flexibility.

The level of physical activity of the elderly is associated with cognitive aspects as physical activity is a protective factor, that is, it enhances in cognitive improvement and also the mental health of the elderly population (de Araujo et al., 2015). Likewise, in the present study, the level of physical activity was compared between the clinical and control groups. This test objective was to verify a possible interference of the level of physical activity in the results related to the association of levels of nicotine dependence and cognitive impairment in the executive domains. The results showed that there was no significant difference in the level of physical activities practiced by the elderly between the clinical and controls; thus, we discarded the hypothesis of interference of this factor in the results observed on the performance of the executive functions by the elderly.
The nutritional status protects against cognitive decay and dementia, the dietary benefits of the elderly reflect cognitive patterns in the cognitive. Individuals with satisfactory intellectual functions have a better diet that is associated with better cognitive performance (Van Dyk \& Sano, 2007; Requejo et al., 2003). We can highlight that the nutritional status of the elderly individual influences the cognitive performance due to the association between diet and cognition, a comparison was made between the nutritional status of the elderly of the clinical group dependent on nicotine and the elderly controls. The result of this comparison between the clinical and control groups resulted in the discarding of the hypothesis of a significant difference in nutritional status between the clinical and control groups that influenced the results of the neuropsychological evaluation.

In an investigation conducted by Collins, Sachs-Ericsson, Preacher, Sheffield, and Markides (2009) 1557 individuals over 65 years of age were evaluated, of which 186 were smokers and 1371 were non smokers. It was observed that smoking increases the risk of cognitive decline. Comparing these results with those of the present study, we observed some similarities. However, we emphasize that ours were stratified according to the different levels of nicotine dependence and even with the size of the differential effect.

Studies comparing cognitive performance between smokers and nonsmokers with measures of nicotine levels obtained mixed results (Gandelman, Newhouse, \& Taylor, 2018). This divergence points out to the complexity of evaluating these domains, especially in the elderly, and the need to improve the work in this area. In order to obtain more robust results, the present study outlined clinical groups and matched controls before performing the hypothesis tests. Thus, the results pointed to a nonsignificant difference between the very low and low nicotine dependent elderly compared to the controls. Also, in the degrees of dependence of medium and high nicotine, the results of the losses to each executive domain were differentiated, as the inhibitory control, being the executive domain with greater loss presenting Cohen's D of 2.17 among the group of elderly dependent high nicotine and control.

In an investigation conducted by Gillum, Kwagyan, and Obisesan (2011), through the evaluation of serum levels of nicotine and the application of the Short Cognitive Function Index in 753 smokers, did not indicate an association between cigarette use, nicotine levels, and cognitive impairments. However, we observed that a global cognitive measurement instrument was used, which did not measure specific cognitive functions and may have generated a bias in the study.

This case-control study on tobacco, levels of nicotine dependence in the elderly associated with the domains of executive functions presents certain limitations. No biomarker was used for nicotine levels, the sample was regional and the number was small. However, the results present 
important data for the elderly population at present on the levels of nicotine dependence associated with impairment in specific domains of executive functions.

Older people have difficulty perceiving cognitive dysfunctions resulting from cigarette smoking. These cognitive deficits are often associated with symptoms of mental illness such as depression. A study in Mexico reported that 1 in 10 seniors used tobacco (Guimaraes Borges et al., 2014; Pinto et al., 2017; Resendiz Escobar et al., 2018).

The development of new models aimed at promoting the quality of life of the elderly population related to tobacco consumption has become a priority today (Vardavas et al., 2017). In this study, the results showed that the elderly who use tobacco and have very low and low levels of nicotine dependence did not present significant differences between the cognitive domains of executive functions compared to the control groups. However, elderly cigarette smokers, with the medium and high degree of nicotine dependence, presented worse performances in the cognitive domains of working memory and inhibitory control compared to the control groups. Thus, clinical and population models of smoking intervention can be reworked with more directive focuses in relation to cognitive impairment in the elderly.

The detection of the level of nicotine dependence is associated with the degree of cognitive impairment in the specific executive domain, which provides a possibility of differential diagnosis, both in the clinical and population contexts, directed at the rehabilitation of the executive domains most affected by smoking in the elderly, and enables the development of more individual and multidisciplinary cognitive neuropsychological rehabilitation strategies in anti-smoking programs implemented in health promotion networks.

\section{Funding}

Fundação de Amparo à Pesquisa do Estado de Minas Gerais, FAPEMIG, Brazil.

\section{Confilcts of interest}

The authors declare they have no conflicts of interest.

\section{Acknowledgments}

Postgraduate Program in Neurosciences at the Universidade Federal de Minas Gerais - UFMG, Belo Horizonte, Brazil. Fundação de Amparo à Pesquisa do Estado de Minas Gerais, FAPEMIG, Brazil.

\section{REFERENCES}

Aguilar-Navarro, S. G., Reyes-Guerrero, J., \& Borgues, G. (2007). Alcohol, tabaco y deterioro cognoscitivo en adultos mexicanos mayores de 65 años. Salud Pública de México, 49(S4), 467-474. doi: 10.1590/S0036-36342007001000005

Almeida, O. P., Hankey, G. J., Yeap, B. B., Golledge, J., \& Flicker, L. (2014). Alcohol consumption and cognitive impairment in older men: A mendelian randomization study. Neurology, 82(12), 1038-1044. doi: 10.1212/WNL.0000000000000255 de Araujo, C. D. C. R., da Silveira, C., Simas, J. P. N., Zappelini, A., Parcias, S R., \& de Azevedo Guimarães, A. C. (2015). Aspectos cognitivos e nível de atividade física de idosos. Revista Saúde (Santa Maria), 41(2), 193-202. doi: $10.5902 / 2236583415705$

Barbosa, M. B., Pereira, C. V., Cruz, D. T. D., \& Leite, I. C. G. (2018). Prevalence and factors associated with alcohol and tobacco use among non-institutionalized elderly persons. Revista Brasileira de Geriatria e Gerontologia, 21(2), 123-133. doi: 10.1590/1981-22562018021.170185

Best, E. A., Juarez-Colunga, E., James, K., LeBlanc, W. G., \& Serdar, B. (2016). Biomarkers of exposure to polycyclic aromatic hydrocarbons and cognitive function among elderly in the United States (National Health and Nutrition Examination Survey: 2001-2002). PloS One, 11(2). doi: 10.1371/journal. pone. 0147632

Borges, R. A., Rech, C. R., Meurer, S. T., \& Benedetti, T. R. B. (2015). Validade e fidedignidade de uma escala para avaliar autoeficácia para a atividade física do idoso. Cadernos de Saúde Pública, 31(4), 701-708. doi: 10.1590/0102$311 \mathrm{X} 00081414$

Campos, C., Lisboa, L. M., \& Westin, R. F. F. (2014). Avaliação clínica do idoso. Brasil: Fundação Hospitalar do Estado de Minas Gerais. Retrieved from http:// www.fhemig.mg.gov.br/acesso-rapido/protocolos-clinicos (Access date: July 2018)

Campos, M. C., Silva, M. L. D., Florêncio, N. C., \& Paula, J. J. D. (2016). Confiabilidade do Teste dos Cinco Dígitos em adultos brasileiros. Jornal Brasileiro de Psiquiatria, 65(2), 135-139. doi: 10.1590/0047-2085000000114

Cantão, L., Fonseca, L. L. K., Silva, T. I. M., Oliveira, M. D., Oliveira, V. D. C. D., \& Machado, R. M. (2015). Socio-demographic and clinical profile of elderly people with depression and the use of psychoactive drugs. Revista da Rede de Enfermagem do Nordeste, 16(3), 355-362. doi: 10.15253/21756783.2015000300008

Collins, N., Sachs-Ericsson, N., Preacher, K. J., Sheffield, K. M., \& Markides, K. (2009). Smoking increases risk for cognitive decline among communitydwelling older Mexican Americans. The American Journal of Geriatric Psychiatry, 17(11), 934-942. doi: 10.1097/JGP.0b013e3181b0f8df

Diamond, A. (2013). Executive functions. Annual Review of Psychology, 64(1), 135168. doi: 10.1146/annurev-psych-113011-143750

Duncan, M. T. (2006). Obtenção de dados normativos para desempenho no teste de Stroop num grupo de estudantes do ensino fundamental em Niterói. Jornal Brasileiro de Psiquiatria, 55(1), 42-48. doi: 10.1590/S004720852006000100006

Farhadian, M., Akbarfahimi, M., Hassani Abharian, P., Hosseini, S. G., \& Shokri, S. (2017). Assessment of executive functions in methamphetamine-addicted individuals: Emphasis on duration of addiction and abstinence. Basic and Clinical Neuroscience, 8(2), 147-154. doi: 10.18869/nirp.bcn.8.2.147

Field, A. P. (2013). Discovering statistics using IBM SPSS statistics, (3th Edition), London, England: SAGE Publications.

Gandelman, J. A., Newhouse, P., \& Taylor, W. D. (2018). Nicotine and networks: Potential for enhancement of mood and cognition in late-life depression. Neuroscience \& Biobehavioral Reviews, 84, 289-298. doi: 10.1016/j. neubiorev.2017.08.018

Gillum, R. F., Kwagyan, J., \& Obisesan, T. O. (2011). Smoking, cognitive function and mortality in a US national cohort study. International Journal of Environmental Research and Public Health, 8(9), 3628-3636. doi: 10.3390/ijerph8093628

Guimaraes Borges, G. L., Mendoza Meléndez, M. Á., López Brambila, M. Á., García Pacheco, J. Á., Velasco-Ángeles, L. R., Beltrán Silva, M. A., ... Camacho Solís, R. (2014). Prevalencia y factores asociados al consumo de tabaco, alcohol y drogas en una muestra poblacional de adultos mayores del Distrito Federal. Salud Mental, 37(1), 15-25. doi: 10.17711/SM.0185-3325.2014.003

Hengstermann, S., Nieczaj, R., Steinhagen-Thiessen, E., \& Schulz, R. J. (2008). Which are the most efficient items of mini nutritional assessment in multimorbid patients?. The Journal of Nutrition Health and Aging, 12(2), 117-122. doi: 10.1007/BF02982563

Machado, T. H., Fichman, H. C., Santos, E. L., Carvalho, V. A., Fialho, P. P., Koenig, A. M., ... Caramelli, P. (2009). Normative data for healthy elderly on the phonemic verbal fluency task-FAS. Dementia \& Neuropsychologia, 3(1), $55-$ 60. doi: 10.1590/S1980-57642009DN30100011 
Mazo, G. Z., \& Benedetti, T. R. B. (2010). Adaptação do questionário internacional de atividade física para idosos. Revista Brasileira de Cineantropometria \& Desempenho Humano, 12(6), 480-484. doi: 10.1590/S198000372010000600013

Melo, D. M. D., \& Barbosa, A. J. G. (2015). O uso do Mini-Exame do Estado Mental em pesquisas com idosos no Brasil: uma revisão sistemática. Ciência \& Saúde Coletiva, 20(12), 3865-3876. doi: 10.1590/1413-812320152012.06032015

North, T. L., Palmer, T. M., Lewis, S. J., Cooper, R., Power, C., Pattie, A., ... Day, I. N. M. (2015). Effect of smoking on physical and cognitive capability in later life: a multicohort study using observational and genetic approaches. BMJ Open, 5(12), e008393. doi: 10.1136/bmjopen-2015-008393

Organização Mundial de Sáude. (2015). Relatório Mundial de Envelhecimento e Saúde. Estados Unidos, 30, 12. Retrieved from http://apps.who.int/iris/ bitstream/handle/10665/186468/who_fwc_alc_15.01_por.pdf;jsessionid=912E F67180E16DC1FAAA783E495E8086? sequence=6. Data de acesso 23/09/2017

Patil, S., Suryanarayana, S., Dinesh, R., Shivraj, N., \& Murthy, N. (2015). Risk factors for falls among elderly: A community-based study. International Journal of Health \& Allied Sciences, 4(3), 135. doi: 10.4103/2278-344x.160867

Pereira, I. F. D. S., Spyrides, M. H. C., \& Andrade, L. D. M. B. (2016). Estado nutricional de idosos no Brasil: uma abordagem multinível. Cadernos de Saúde Pública, 32(5), doi: 10.1590/0102-311x00178814

Pinto Gomide, H., Rodrigues Teixeira de Carvalho, C., Lovisi Menezes, M., Gazolla de Oliveira, I., Furtado de Mendonça, G., Duque de Albuquerque Júnior, R., ... Mota Ronzani, T. (2017). Depression among smokers of a web-based intervention to quit smoking: a cross-sectional study. Salud Mental, 40(6), 271277. doi: 10.17711/SM.0185-3325.2017.035

Requejo, A. M., Ortega, R. M., Robles, F., Navia, B., Faci, M., \& Aparicio, A. (2003). Influence of nutrition on cognitive function in a group of elderly, independently living people. European Journal of Clinical Nutrition, 57(1), S54-S57. doi: 10.1038/sj.ejcn.1601816

Reséndiz Escobar, E., Bustos Gamino, M. N., Mujica Salazar, R., Soto Hernández, I. S., Cañas Martínez, V., Fleiz Bautista, C., ... Villatoro Velázquez, J. A. (2018).
National trends in alcohol consumption in Mexico: results of the National Survey on Drug, Alcohol and Tobacco Consumption 2016-2017. Salud Mental, 4l(1), 7-15. doi:10.17711/SM.0185-3325.2018.003

Salgado, J. V., Malloy-Diniz, L. F., Campos, V. R., Abrantes, S. S. C., Fuentes, D., Bechara, A., \& Correa, H. (2009). Neuropsychological assessment of impulsive behavior in abstinent alcohol-dependent subjects. Revista Brasileira de Psiquiatria, 31(1), 4-9. doi: 10.1590/S1516-44462009000100003

Scherder, E. J., Van Paasschen, J., Deijen, J. B., Van Der Knokke, S., Orlebeke, J. F. K., Burgers, I., ... Sergeant, J. A. (2005). Physical activity and executive functions in the elderly with mild cognitive impairment. Aging \& Mental Health, 9(3), 272-280. doi: 10.1080/13607860500089930

Swan, G. E., \& Lessov-Schlaggar, C. N. (2007). The effects of tobacco smoke and nicotine on cognition and the brain. Neuropsychology Review, 17(3), 259-273. doi: 10.1007/s11065-007-9035-9

Tabachnick, B. G., \& Fidell, L. S. (2013). Using Multivariate Statistics, (6th ed). Boston, MA: Pearson.

Van Dyk, K., \& Sano, M. (2007). The impact of nutrition on cognition in the elderly. Neurochemical Research, 32(4-5), 893-904. doi: 10.1007/s11064-006-9241-5

Vardavas, C. I., Agaku, I., Filippidis, F., Kousoulis, A. A., Girvalaki, C., Symvoulakis, E., ... Lionis, C. (2017). The Secondhand Smoke Exposure Scale (SHSES): A hair nicotine validated tool for assessing exposure to secondhand smoke among elderly adults in primary care. Tobacco Prevention \& Cessation, 3, 9. doi: $10.18332 / \mathrm{tpc} / 69850$

Wang, Y., \& Andrade, L. H. (2013). Epidemiology of alcohol and drug use in the elderly. Current Opinion in Psychiatry, 26(4), 343-348. doi: 10.1097/ YCO.0b013e328360eafd

Wolf, I. K., Du, Y., \& Knopf, H. (2017). Changes in prevalence of psychotropic drug use and alcohol consumption among the elderly in Germany: Results of two National Health Interview and Examination Surveys 1997-99 and 2008-11. BMC Psychiatry, 17(1), 90. doi: 10.1186/s12888-017-1254-x 